\title{
Fluorescence Detection of Hydroxyl Radicals in Water Produced by Atmospheric Pulsed Discharges
}

\author{
S. Li ${ }^{1}$, I. V. Timoshkin', M. Maclean ${ }^{1,2}$, S. J. MacGregor ${ }^{1}$, M. P. Wilson ${ }^{1}$, M. J. Given ${ }^{1}$, \\ T. Wang ${ }^{1}$ and J. G. Anderson ${ }^{1}$ \\ ${ }^{1}$ Department of Electronic and Electrical Engineering, University of Strathclyde, Glasgow, G1 1XW, UK \\ ${ }^{2}$ Department of Biomedical Engineering, University of Strathclyde, Glasgow, G4 0NW, UK
}

\begin{abstract}
It has been proven that hydroxyl $(\mathrm{OH})$ radicals can be generated by streamer discharges across water surfaces under ambient atmospheric conditions. Hydroxyl radicals have the highest oxidation capability amongst all oxygen-based reactive species, thus $\mathrm{OH}$ play an important role in oxidation of organic molecules and the bactericidal effects of plasma discharges. In this study, generation of hydroxyl radicals in water by pulsed streamer discharges was investigated. Terephthalic acid was used as a chemical probe as this acid is converted into 2-hydroxyterephthalic acid (HTA) by chemical reaction with $\mathrm{OH}$ radicals. The concentration of $\mathrm{OH}$ radicals was quantified by measuring the fluorescence light intensity generated by HTA molecules in water solutions. Both positive and negative pulsed discharges with different voltage levels were tested. Two different types of sample holder - non-conductive plastic dishes, and dishes lined with conductive aluminum foil were used in order to investigate the effect of the discharge propagation path on the efficiency of $\mathrm{OH}$ production. The efficiency of $\mathrm{OH}$ production was measured as a function of: the distance between the needle electrode and the water surface; the magnitude and polarity of HV energization; and the total delivered charge. The obtained results will help in optimization of non-thermal plasma systems for chemical and biological decontamination.
\end{abstract}

Index Terms - Streamer discharges, $\mathbf{O H}$ radicals, Fluorescence.

\section{INTRODUCTION}

OVER recent years, strong interest in the microbiological and chemical actions of non-thermal plasmas has resulted in the development of a number of potential practical (environmental and medical) applications of such plasma discharges. Atmospheric-pressure plasma discharges including plasma jets, plasma bullets, and transient and steady-state corona discharges in ambient air, produce strong biological and chemical oxidation effects [1,2], which provide a basis for chemical, environmental and medical plasma-based technologies. It has been proven that low-temperature atmospheric plasmas (including corona discharges in air) generate charged particles and reactive oxygen and nitrogen species, including groundstate oxygen, superoxide, singlet oxygen, ozone, hydrogen peroxide, hydroxyl radicals, nitric oxide, and nitrogen dioxide. These reactive species, together with UV photons and strong electric fields, lead to the bactericidal and oxidative action of such non-thermal plasmas. It has also been shown that, in the case of air-based non-thermal plasmas, the reactive chemical species are the main contributor to the process of bacterial inactivation, $[3,4]$. However, despite significant efforts to

Manuscript received on 16 December 2014, in final form 19 May 2015, accepted 19 May 2015. investigate the bio-decontamination effects of atmospheric nonthermal plasmas, further understanding of the production of the reactive species has been identified as one of the main challenges related to the successful use of such plasmas in environmental and medical applications, [5]. It has been demonstrated that in the case of non-thermal atmospheric air plasmas, or plasmas in which oxygen is used as a component of the gaseous environment, reactive oxygen species may have a dominant effect in the inactivation processes. For example, a correlation between ozone generation and the bactericidal efficacy of atmospheric corona discharges is discussed in [6]. Ozone was used as an indicator of the generation of reactive oxygen species, and the role of each individual species was not determined. There is a strong indication that hydroxyl radicals produced by non-thermal plasma discharges make a significant contribution to the biological damage. In [7], the authors argue that $\mathrm{OH}$ radicals, produced in humid air by a dielectric barrier discharge through direct chemical reactions with water molecules, play the main role in the inactivation of Geobacillus stearothermophilus spores. Paper [8] states that, in the case of non-thermal plasma in air with a high relative humidity (the authors used air with a relative humidity up to $70 \%), \mathrm{OH}$ radicals quickly take part in chemical reactions (their halfperiod life in biological cells is $1 \mathrm{~ns}$ ), and generate significant 
amount of peroxides which make a contribution to the inactivation of Bacillus atrophaeus spores. The authors of [9] investigated the efficiency of producing $\mathrm{OH}$ radicals in air by pulsed discharges, and found that the efficiency of the generation of hydroxyl radicals in atmospheric air depends on its humidity, and has a maximum at $\sim 55 \% \mathrm{rh}$.

Their short lifetime and relatively low concentrations mean that $\mathrm{OH}$ radicals may not be detected in optical emission plasma spectra, and the authors of [9] reported that they were not able to observe the $\mathrm{OH}$ emission line at $308.9 \mathrm{~nm}$. However, in the case of more intensive transient spark discharges in atmospheric air, the $\mathrm{OH}$ emission line at $308.9 \mathrm{~nm}$ was clearly detected, which indicates that such non-thermal plasma discharges are capable of generating a significant concentration of $\mathrm{OH}$ radicals in gaseous medium [10]. As indicated in [11], the concentration of $\mathrm{OH}$ radicals in non-thermal plasma can be $10^{13}-10^{15} \mathrm{~cm}^{-3}$.

In [11], OH radicals have been identified as one of the main reactive oxygen species produced by transient corona discharges in air. The authors describe $\mathrm{OH}$ radicals as extremely reactive and able to trigger oxidation reactions in the lipid layer of bio-membrane. The review paper [12] also indicates that in numerous studies $\mathrm{OH}$ radicals are considered the main contributor to the bactericidal effects of non-thermal atmospheric plasmas. Therefore, it can be stated that in the case when plasmas are developed in humid atmospheric air, or in contact with water or water-based surfaces, $\mathrm{OH}$ radicals make a significant contribution to the biological and chemical [30] effects of plasma. However, the exact role and mechanism of the hydroxyl radicals in plasma action, $\mathrm{OH}$ production rates, and their migration capabilities in water or water-based solutions, are not fully known.

The present paper is focused on investigating the generation of $\mathrm{OH}$ radicals in water-based solutions by transient atmospheric plasma (streamer) discharges. It is important to understand the role of the high voltage wave-forms (their polarity, duration, voltage and current magnitudes) and test cell topologies, in the efficiency of the production of $\mathrm{OH}$ radicals, in order to optimize the parameters of transient plasmas required for different practical applications.

The hydroxyl radical can be formed through different mechanisms, including direct electronic excitation of water molecules and dissociative recombination of exited water molecules, [13-15]:

$$
\begin{aligned}
& \mathrm{H}_{2} \mathrm{O}+\mathrm{e}^{-} \rightarrow \mathrm{OH}+\mathrm{H}+\mathrm{e}^{-} \\
& \mathrm{H}_{2} \mathrm{O}^{+}+\mathrm{e}^{-} \rightarrow \mathrm{OH}+\mathrm{H} \\
& \mathrm{H}_{2} \mathrm{O}^{+}+\mathrm{H}_{2} \mathrm{O} \rightarrow \mathrm{H}^{+}\left(\mathrm{H}_{2} \mathrm{O}\right)+\mathrm{OH}
\end{aligned}
$$

Other mechanisms of formation of the hydroxyl radical in plasma-treated water solutions can involve formation and subsequent dissociation of peroxynitrous acid and/or peroxynitrite, as discussed in [31]. Peroxynitrous acid and peroxynitrite can be formed in an acidic environment through reaction between nitrite, hydrogen peroxide and $\mathrm{H}^{+}$ions; decomposition of this acid and its conjugate (peroxynitrite) base then results in formation of $\mathrm{OH}$ and $\mathrm{NO}_{2}$ radicals [31]. As indicated in [2] and [31], these complex processes of formation of $\mathrm{OH}$ radicals through chemical reactions involving nitrites, nitrates, hydrogen peroxide and ozone are not fully understood and further investigations are needed: for example, direct measurements of the main chemical species generated by plasma discharges (hydrogen peroxide and others) could be importart for further understanding of these plasma-induced chemical processes in water-based solutions.

Therefore, $\mathrm{OH}$ radicals may be produced by plasma in air above the sample surface, and these radicals may diffuse into the liquid sample (if their half-life will be sufficient for such processes) [16]. Diffused $\mathrm{OH}$ radicals will then react with water molecules, resulting in production of hydrogen peroxide, which will be involved in the chemical reactions discussed above. Alternatively, $\mathrm{OH}$ radicals can be produced directly in the liquid in the case of contact between plasma and a water/waterbased solution surface, according to the chemical reactions in equation (1).

Due to a short half-life time and the highly reactive nature of hydroxyl radicals, it is difficult to detect plasma-produced $\mathrm{OH}$ species in aqueous solutions. $\mathrm{OH}$ radicals can quickly form $\mathrm{H}_{2} \mathrm{O}_{2}$ or other products by recombination or oxidation reactions. In order to detect and to measure the concentration of $\mathrm{OH}$ radicals, different approaches have been used, including laserinduced fluorescence techniques [16], light emission spectroscopy [17], electron paramagnetic resonance spectroscopy [32] and use of chemical probes [18].

A method which is based on using terephthalic acid (TA) as a chemical probe was suggested in $[19,20]$. TA acid reacts specifically with $\mathrm{OH}$ radicals, transforming into 2-hydroxylterephtalic acid (HTA) through addition of $\mathrm{OH}$ to its aromatic ring. When excited with light of $\sim 310 \mathrm{~nm}$ wavelength, HTA molecules generate a strong fluorescent signal with a peak at $425 \mathrm{~nm}$ which can be readily detected and measured. The intensity of this fluorescence signal is directly related to the HTA concentration in the tested liquid. Therefore, the concentration of $\mathrm{OH}$ radicals in this liquid can be quantified if the HTA concentration is known. The use of TA as a chemical probe is an efficient way to detect plasma-generated $\mathrm{OH}$ radicals, as terephthalic acid is a highly selective and sensitive $\mathrm{OH}$ scavenger, [18]: $\mathrm{OH}$ radicals can react with TA molecules before they form other products; other reactive oxygen species, even those with a high oxidative potential such as ozone, will not react with TA.

In the present study, HV impulses of both polarities, and with different peak voltages, were used to produce transient plasma (spark) discharges. Transient atmospheric plasma discharges have been selected for this study due to their high bioinactivation capability: it has been shown in [10] that such transient sparks demonstrate a higher bactericidal efficiency as compared with corona discharges. In the present paper, the efficiency of $\mathrm{OH}$ production in water-based solutions by the transient plasma discharges was obtained as a function of peak voltage level, polarity, total delivered charge, and discharge propagation path. 


\section{EXPERIMENTAL SYSTEM 2.1 TREATMENT CELL AND ENERGIZATION SYSTEM}

An $80 \mathrm{~mm}$ high Perspex cylinder with a diameter of 150 $\mathrm{mm}$ and two nylon flanges was used as the test cell body. The high voltage (HV) electrode, a gramophone needle with a body diameter of $1.2 \mathrm{~mm}$ and a tip radius of $\sim 36 \mu \mathrm{m}$, was fixed in the upper nylon flange, which could be screwed in or out of the test cell, thus providing the ability to change the distance between the electrode and the sample surface. A grounded electrode (aluminum plate with a thickness of $10 \mathrm{~mm}$, external diameter of $120 \mathrm{~mm}$ ) was placed at the bottom of the test cell. Plastic dishes with an internal diameter of $55 \mathrm{~mm}$ were used to hold liquid samples on top of the grounded electrode. The HV electrode was stressed with positive and negative HV impulses, and was located above the surface of water-based solutions. The distance between the HV electrode and the liquid surface was varied from $\sim 11 \mathrm{~mm}$ till $0 \mathrm{~mm}$ (the electrode was in contact with the surface of the liquid sample). Two different types of liquid container were used in this work: non-conductive plastic dishes and plastic dishes lined with a grounded aluminum foil (conductive dishes). During the tests, both the conductive and non-conductive sample holders were filled with $6 \mathrm{ml}$ TA waterbased solution. These topologies were used in order to compare the efficiency of $\mathrm{OH}$ production in two different cases. An air pump (VP 1HV, KNF Neuberger Ltd) was used to gently flush the test cell with ambient laboratory air with a relative humidity of $\sim 40 \%$. Ozone concentration during plasma treatment was monitored by an ozone analyzer IN-2000 LOCON, IN USA Inc.

Transient plasma impulses were generated by energization of a $\mathrm{HV}$ electrode with HV impulses produced by a pulsed power generator (Samtech Ltd, Scotland). This pulsed power supply, based on a high voltage autotransformer, is capable of delivering voltage impulses with a magnitude up to $30 \mathrm{kV}$, and a rate of rise of $\sim(3-5) \cdot 10^{2} \mathrm{kV} / \mathrm{ms}$, [21]. The pulse repetition rate used in the present work was 20 pulses per second. A high voltage probe (Tektronix P6015A, with bandwidth of $75 \mathrm{MHz}$ ) was used to monitor the high voltage wave-forms. The transient current in the discharge circuit was measured using a Pearson current monitor, model 6585 with a bandwidth of 250 MHz. Both high voltage and current waveforms were recorded using a Tektronix TDS 2024 digitizing oscilloscope (200 MHz bandwidth, 2 GSamples/sec sampling rate). The HV and current probes were connected to the oscilloscope using $50 \Omega$ BNC cables. Schematic diagram of the test cell is shown in Figure 1a.

The cross-sections of the plastic dishes and the HV electrode used for generation of the transient plasma discharges and treatment of liquids are shown in Figures $1 \mathrm{~b}$ and $1 \mathrm{c}$. In the first case (Figure 1b), non-conductive plastic dishes were filled with liquid samples and were placed on a grounded metal plate. In this topology, discharges propagate from the HV needle electrode down to the surface of the liquid sample, then discharges continue to develop across the liquid/air interface towards the border of the plastic dish, and finally they reach the grounded plate.

(a)
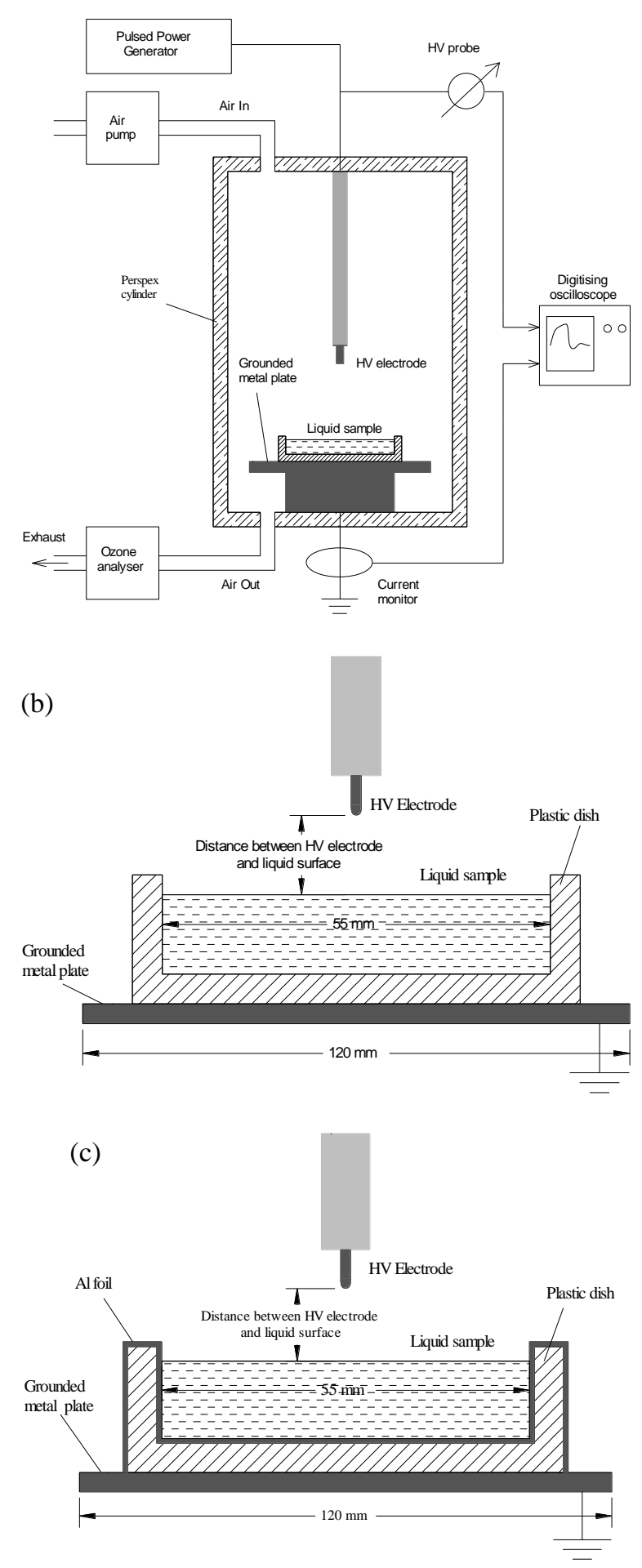

Figure 1. Cross-section of the treatment cells; (a) Schematic diagram of the experimental set-up; (b) plastic dish filled with the liquid sample (nonconductive dish); (c) plastic dish lined with aluminium foil and filled with the liquid sample (conductive dish).

In the second case (Figure 1c), water-based solutions were placed in plastic dishes lined with a grounded aluminum foil (which acted as conductive dishes). As in the previous topology, the HV electrode was located directly above the center of the plate. In the case of the conductive dishes (Figure 1c), the discharges propagate straight down to the liquid surface, then the ionic current flows through the liquid sample towards the 
aluminum foil, which is grounded by direct contact with the grounded metallic support plate. In the case of the nonconductive dishes, when the HV electrode was in contact with the liquid surface discharges were generated at the air/liquid interface, these discharges propagated along this interface and the border of the dish towards the grounded plate. Alternatively, in the case of the conductive dishes, when the HV electrode was in contact with the liquid, all discharge activity and ionic conduction took place in the liquid, and no visible discharges across the liquid/air interface were observed.

\subsection{CURRENT AND VOLTAGE WAVE-FORMS}

One of the main parameters in this set-up which influences the high voltage and current waveforms is the distance between the HV needle tip and the surface of the liquid sample. The impulsive breakdown voltage varies with this distance. Table 1 shows the obtained breakdown voltages for different distances and topological configurations.

Table 1. Breakdown voltage for different distances between the HV needle electrode and liquid surface in the two types of sample holder.

\begin{tabular}{l|l|l}
\hline Voltage, $(\mathrm{kV})$ & $\begin{array}{c}\text { Non-conductive plastic } \\
\text { dish, }(\mathrm{mm})\end{array}$ & $\begin{array}{c}\text { Conductive (Al-foil } \\
\text { lined) dish, }(\mathrm{mm})\end{array}$ \\
\hline+20 & 0.53 & 4.98 \\
\hline+24 & 5.06 & 7.73 \\
\hline+28 & 7.25 & 11.06 \\
\hline-20 & 0.68 & 1.72 \\
\hline-24 & 1.37 & 3.32 \\
\hline-28 & 3.65 & 6.03 \\
\hline
\end{tabular}

As Table 1 shows, the breakdown distance using the nonconductive dish is much shorter than the distance using the foillined conductive dish, under the same breakdown voltage level. Tests with zero gap between the HV electrode and the sample surface (the HV electrode was in contact with the liquid) were also conducted for both types of sample holder.

Figure 3 shows typical voltage and current waveforms for the conductive and non-conductive dishes, with the $\mathrm{HV}$ electrode energized with $\pm 24 \mathrm{kV}$. As shown in Figures $3 \mathrm{a}$ and $3 \mathrm{~b}$, multiple peaks were observed in the voltage and current waveforms in the case of the non-conductive dish. This indicates multiple transient streamers (flashes) before the main voltage collapse, i.e. the development of a transient spark which can be referred to as a complete breakdown in the gap between the HV and ground electrodes. For this type of sample holder the breakdown path includes the vertical path through air between the HV needle tip and the liquid surface, and the path across the air/liquid interface.

Figure 3 shows typical voltage and current waveforms for the conductive and non-conductive dishes, with the $\mathrm{HV}$ electrode energized with $\pm 24 \mathrm{kV}$. As shown in Figures $3 \mathrm{a}$ and $3 \mathrm{~b}$, multiple peaks were observed in the voltage and current waveforms in the case of the non-conductive dish. This indicates multiple transient streamers (flashes) before the main voltage collapse, i.e. the development of a transient spark which can be referred to as a complete breakdown in the gap between the HV and ground electrodes. For this type of sample holder the breakdown path includes the vertical path through air between the HV needle tip and the liquid surface, and the path across the air/liquid interface.

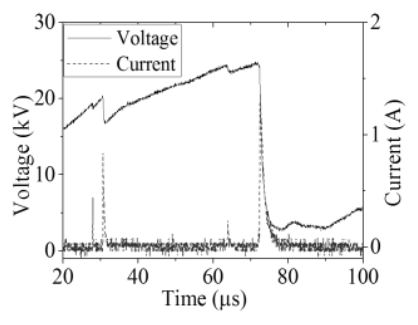

(a)

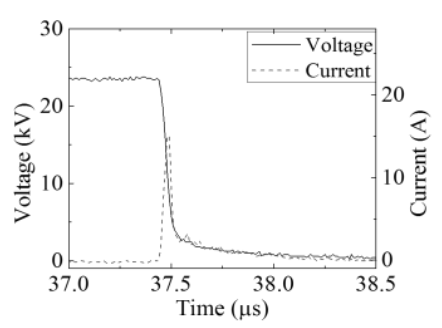

(c)

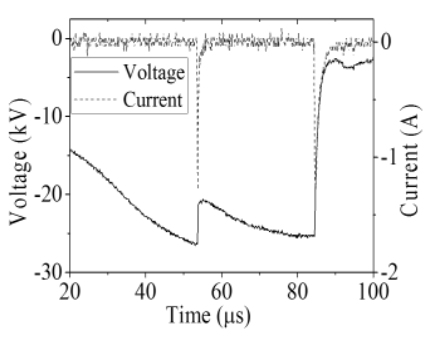

(b)

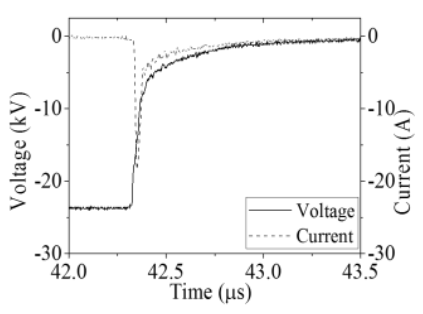

(d)
Figure 3. Voltage and current waveforms: (a) $+24 \mathrm{kV}$ non-conductive plastic dish; (b) - $24 \mathrm{kV}$ non-conductive plastic dish; (c), $+24 \mathrm{kV}$ conductive foil-lined dish; (d), -24 kV conductive foil-lined dish.

As can be seen from Figure 3, the peak discharge current in the case of non-conductive dishes is $\sim 1.36 \mathrm{~A}$, (breakdown voltage $+24.6 \mathrm{kV}$ ), the duration of the current impulse is $\sim 10 \mu \mathrm{s}$. This peak current is much lower compared with the discharge current in the case of the conductive foil-lined dish, $\sim 16.16 \mathrm{~A}$ (breakdown voltage $+23.8 \mathrm{kV}$ ), however in this case the current pulse is much shorter, $\sim 1 \mu \mathrm{s}$. Moreover, only a single main voltage collapse was observed in the case of the conductive sample dishes (no pre-breakdown transient events), which indicates only a single breakdown path/event between the highvoltage needle and the liquid surface. Also, it was observed that the peak current increases with increasing applied voltage.

However, taking into consideration all these factors (appearance of multiple current peaks, different duration of current impulses in different topologies) it was decided to investigate the efficiency of $\mathrm{OH}$ production as a function of the total charge delivered during each high-voltage impulse, rather than the peak magnitude of individual current pulses. The total delivered charge was calculated by integration of the current waveforms. The results of this analysis $(\mathrm{OH}$ production as a function of the total charge in different topologies) are presented in Section 3.5.

\section{FLUORESCENT LIGHT EMISSION}

Terephthalic acid, $\mathrm{C}_{6} \mathrm{H}_{4}(\mathrm{COOH})_{2}$, (Sigma-Aldrich Ltd., 99+\% purity) was used in the current work for detection of $\mathrm{OH}$ radicals in water. As discussed in Section $\mathrm{I}$, this acid reacts specifically with $\mathrm{OH}$ radicals to produce 2-hydroxyterephthalic acid, $\mathrm{C}_{8} \mathrm{H}_{6} \mathrm{O}_{5}$. Other reactive oxygen species such as ozone or hydrogen peroxide don't directly react with TA acid, [16, 18]. 
While TA molecules don't produce fluorescent light, molecules of HTA generates strong fluorescent light emission with a peak at $425 \mathrm{~nm}$ when excited with UV-A light and their concentration can be obtained by measuring the intensity of the fluorescence light signal. After that, using a calibration curve (fluorescent light emission as a function of HTA concentration) and the conversion rate of $\mathrm{OH}$ radicals into HTA acid, the concentration of $\mathrm{OH}$ radicals can be calculated. In the present work, water based solutions with $2 \mathrm{mM}$ concentration of TA acid were treated with transient plasma discharges (similar TA concentration was used in [19]). Water based TA solutions were prepared by dissolving $66 \mathrm{mg}$ of TA acid in a $200 \mathrm{ml}, 5$ $\mathrm{mM} \mathrm{NaOH}$ (distilled) water solution. Then $6 \mathrm{ml}$ of TA solution was placed into non-conductive or conductive dishes for treatment.

After the plasma treatment, the solution was transferred into plastic cuvettes and the fluorescent light emission was measured using a spectrofluorophotometer Shimadzu RF5301PC. The excitation wavelength was $310 \mathrm{~nm}$ and the peak of the fluorescence signal was detected at $425 \mathrm{~nm}$. Also, the $\mathrm{pH}$ of plasma treated TA solutions was measured using a $\mathrm{pH}$ meter (Hanna Instruments PH 210).

\subsection{UNTREATED TA SOLUTION}

To confirm that TA acid does not produce fluorescent light, an untreated TA solution was examined. As expected, no pronounced fluorescence light emission at $425 \mathrm{~nm}$ was detected in the case of untreated samples. Low readings of 40-50 a.u. at this wavelength were used as a baseline (control) to compare with signals obtained from plasma treated samples.

\subsection{TA SOLUTION TREATED IN NON-CONDUCTIVE DISHES}

$6 \mathrm{ml}$ of a water based, $2 \mathrm{mM}$, TA solution was transferred into a non-conductive dish and placed in the centre of the treatment chamber on the grounded metallic surface, directly under the $\mathrm{HV}$ needle electrode and treated for 1, 3, 5 and 7 minutes. The needle electrode was stressed with HV impulses of both polarities, with peak voltages of $20 \mathrm{kV}, 24 \mathrm{kV}$ and 28 $\mathrm{kV}$. The liquid samples were then transferred into cuvettes and the fluorescence light emission spectra were recorded.

Figure 4 summaries the results of the fluorescent light peak measurements for different voltage levels and different polarity of the HV impulses. There is an almost linear increase in the magnitude of the fluorescent signal with an increase in the duration of treatment. This tendency was observed for both polarities. However, there is no major difference in the fluorescent light signal intensity for different voltage levels.

A potential reason for this effect is the difference in the distance between the HV needle and the sample surface: higher voltages produce more intensive plasma discharges, however the distance between the needle and the surface is longer and the active species travel a longer distance before they reach the liquid sample. It is expected that, due to reaction processes in the air above the liquid surface, not all particles are able to reach the liquid. Conversely, for lower voltages, this distance is shorter, and a higher number of active particles produced by the plasma discharges can reach the liquid surface. Thus, these two factors may compensate each other, resulting in a similar intensity of the fluorescent signals for different voltages at the same treatment time. The same factors are potentially responsible for the higher fluorescence signal from samples treated with negative impulses as compared with positive impulses (Figure 4). In the case of HV impulses with negative polarity, the distance between the HV needle and the surface of the water sample is shorter as compared with the case of positive impulses (at the same level of breakdown voltage), Table 1. Thus, more chemically-active species will be produced in liquid samples in the case of shorter distances between the $\mathrm{HV}$ electrode and the liquid surface.
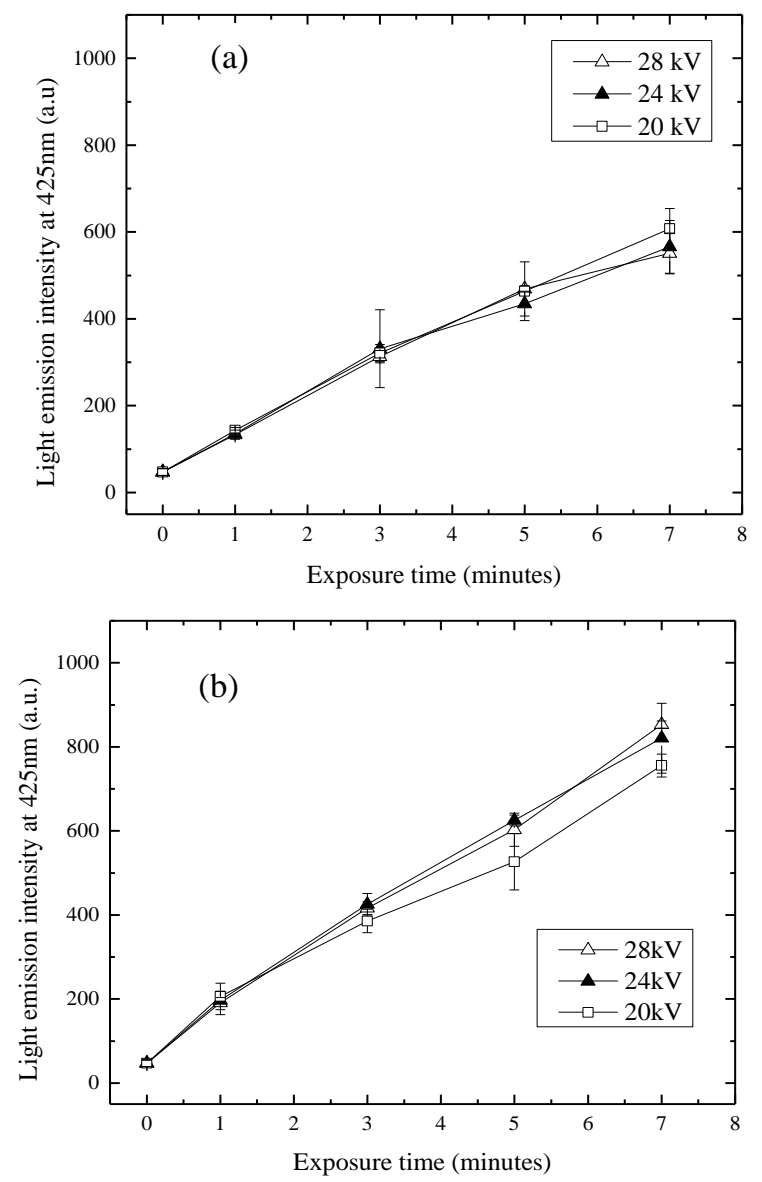

Figure 4. Fluorescence light intensity of samples treated with impulsive discharges in non-conductive dishes as a function of treatment time and voltage levels. (a) positive discharges; (b) negative discharges.

The acidity of the plasma treated TA solution sample was examined. The $\mathrm{pH}$ of TA solutions treated in non-conductive dishes with both positive and negative transient plasma discharges, reduced from $\sim 10.9$ (untreated liquid) to $\sim 10.3$ (7 min plasma treatment). The high $\mathrm{pH}$ of the original untreated samples is explained by the addition of $\mathrm{NaOH}$ to the solutions, as TA acid is poorly soluble in water. No major difference in acidity levels for positive and negative energization was observed. A similar decrease in the $\mathrm{pH}$ of water treated with plasma was reported in [14-16], and this increase in acidity of plasma-treated samples may be explained by the production of 
$\mathrm{H}^{+}$ions. One mechanism of production of these ions is dissociation of water molecules, (Eq. (1)). Other routes of production of $\mathrm{H}^{+}$ions may include dissolution and dissociation in water solutions of nitrogen oxides produced by plasma with formation of nitrites and nitrates together with $\mathrm{H}^{+}$ions, [2], [31]:

$$
\begin{aligned}
& \mathrm{NO}_{2}+\mathrm{NO}_{2}+\mathrm{H}_{2} \mathrm{O} \rightarrow \mathrm{NO}_{2}^{-}+\mathrm{NO}_{3}{ }^{-}+2 \mathrm{H}^{+} \\
& \mathrm{NO}+\mathrm{NO}_{2}+\mathrm{H}_{2} \mathrm{O} \rightarrow 2 \mathrm{NO}_{2}{ }^{-}+2 \mathrm{H}^{+}
\end{aligned}
$$

In [31], it is shown that low-acidity liquids (buffer solution) treated with plasma discharges demonstrated higher concentration of nitrites, lower concentration of hydrogen peroxide and significantly lower decrease in $\mathrm{pH}$, as compared with water. This result is correlated with the relatively small reduction in the $\mathrm{pH}$ value of plasma-treated TA solutions obtained in the present paper.

\subsection{TA SOLUTION TREATED IN CONDUCTIVE DISHES}

In order to investigate the efficiency of $\mathrm{OH}$ production by plasma discharges in the case when the discharge current passes through the sample directly, conductive foil-covered dishes were used.

$6 \mathrm{ml}$ samples of $2 \mathrm{mM}$ TA solution were placed in the conductive dishes and located in the centre of the test cell, beneath the HV electrode (Figure 1c). The needle was stressed with the same HV impulses as used with the plastic dishes. Visual observation confirmed that bright transient plasma discharges propagate vertically and hit the sample surface: as in the case of conductive dishes, no streamers across the air/liquid interface were observed. After treatment with HV impulses, the samples were transferred into cuvettes and fluorescence light emission was measured.

Figure 5 shows the peak magnitude of the light fluorescence as a function of the treatment time, polarity, and peak voltage of the HV impulses. Figure 5 demonstrates that the peak fluorescent light intensity is an almost linear function of the treatment time for both polarities. However, there is a clear indication that the plasma discharges generated with higher voltages produce fluorescent light with a higher intensity. This tendency is especially noticeable in the case of negative energization of the HV electrode. Also, due to the high intensity of fluorescent light emitted by TA solutions treated for 5 and 7 min with $-28 \mathrm{kV}$ discharges, and those treated for $7 \mathrm{~min}$ with $24 \mathrm{kV}$ discharges, it was not possible to measure the peak magnitude due to saturation of the fluorescent signal.

The $\mathrm{pH}$ of the plasma treated TA solutions in conductive dishes reduces with an increase in the duration of plasma treatment, however this decrease is more pronounced than that observed when treated in non-conductive dishes: $\mathrm{pH}$ of the samples treated with conductive dishes decreases from 10.9 (prior to the plasma treatment) to $9.8-9.2$ (7 $\mathrm{min}$ plasma treatment). This is further confirmation that direct discharges in the case of the foil-lined conductive dishes resulted in a higher concentration of reactive species delivered into the water.
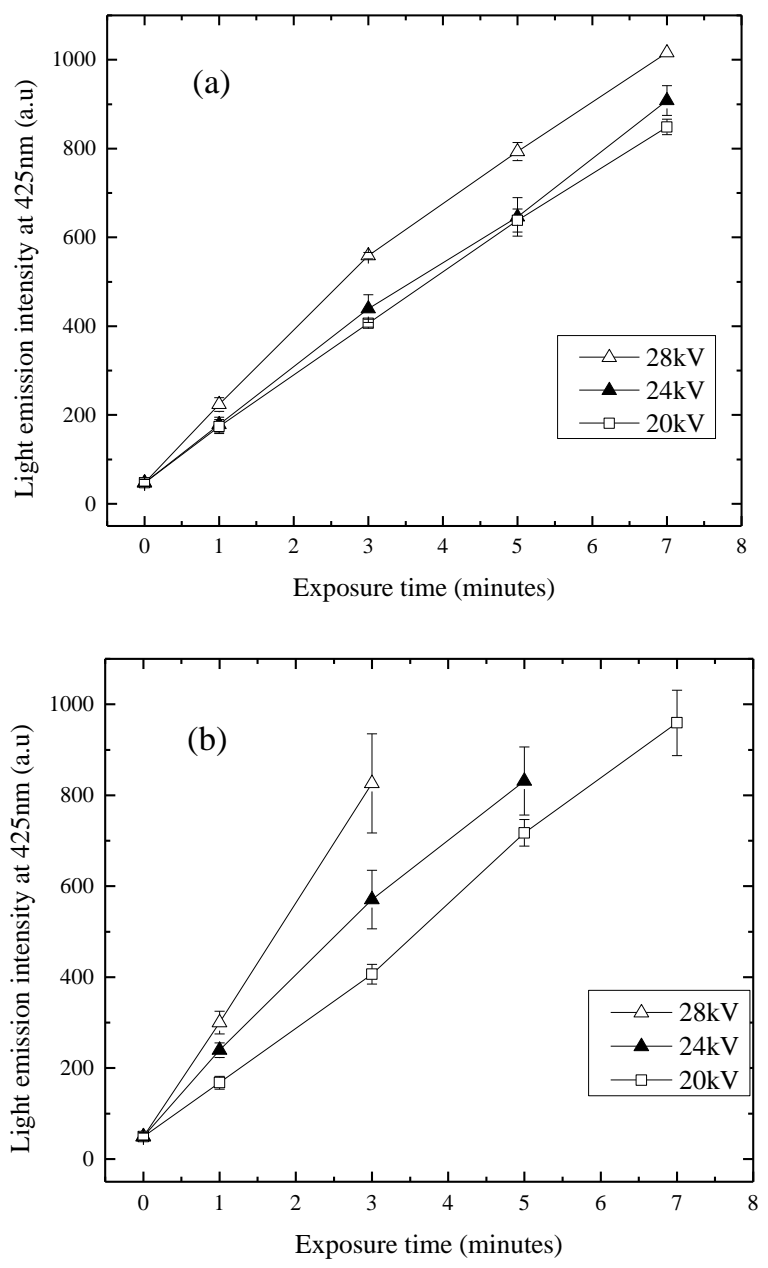

Figure 5. Fluorescent light intensity of TA solutions treated with impulsive plasma in conductive foil-covered dishes. Magnitude of the fluorescent light as function of treatment time for (a), positive energization; (b), negative energization.

It can be noted that in the case of conductive dishes, the intensity of the fluorescence signals is stronger than in the case of the non-conductive dishes. Also, in the former case, a more pronounced separation between fluorescence light emission curves for different energization voltages is observed. This separation can potentially be explained by the difference in the distances between the HV electrode and the liquid surface for positive and negative impulses at the same voltage level. As can be seen from Table 1, negative impulses require substantially lower distances as compared with positive impulses, in order to achieve the same breakdown voltage. Moreover, in the case of non-conductive dishes, the relative difference in the total length of the discharge path (in air and across the air/liquid interface) for the lowest and highest voltages is $\sim 10 \%$, while the relative difference in the discharge path for the lowest and highest voltages in the case of conductive dishes (which is only the vertical path through air) is substantially larger, $\sim 70 \%$. Thus, it may be argued that, in this case, production of $\mathrm{OH}$ radicals is more sensitive to changing distance between the $\mathrm{HV}$ electrode and the surface of the liquid, resulting in larger separation between the fluorescence curves for different energization voltages. However, further investigation is required to establish 
the exact reason for this effect, which may involve measurements of other reactive chemical species produced in water-based solutions by transient plasma discharges.

\subsection{HV ELECTRODE IN CONTACT WITH THE SAMPLE}

It is known that plasma discharges which are generated directly in water can produce highly reactive species including $\mathrm{OH}$ radicals, [22-24]. In order to compare the efficiency of $\mathrm{OH}$ radical production by the plasma transient discharges generated above water and in the case when the high tension electrode is in direct contact with the liquid surface, the needle HV electrode was lowered down until it was in contact with the treated liquid. In this case, there is no air gap and the HV electrode was energized with $\pm 18 \mathrm{kV}$ voltage impulses, using non-conductive dishes (plasma discharges propagate across air/liquid interface only).

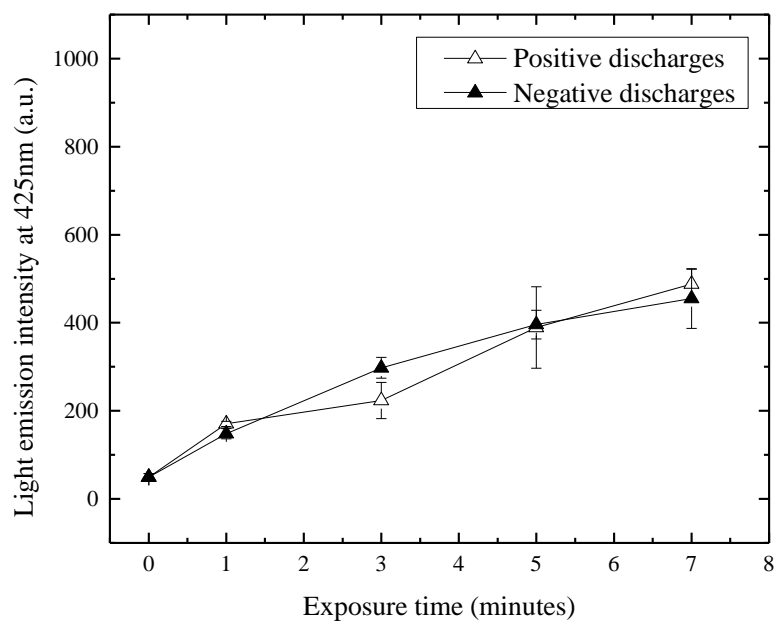

Figure 6. Fluorescence light intensity as a function of treatment time in the case of direct contact of the high tension electrode with the TA solution surface. $\pm 18 \mathrm{kV}$, non-conductive dish.

Figure 6 shows the peak fluorescent light emission as a function of treatment time for the non-conductive dishes. It can be seen that the intensity of the fluorescent signal is lower than in the case of discharges with the air gap between the sample surface and the HV electrode. For negative energization, the magnitude of the peak fluorescent signal after 7 min plasma treatment is almost twice lower than that for the air gap topology used in Section 3.2, for the same treatment time. Also, in the case of the direct contact of the high tension electrode and the liquid surface, no difference in the intensity of the fluorescent light was observed for positive and negative energization.

These results confirm that the reactive species responsible for the production of $\mathrm{OH}$ radicals (and $\mathrm{OH}$ radicals themselves) are generated in both sections of the transient plasma path: the vertical path section (propagation through air) and the horizontal path section (across the air/liquid interface in the case of non-conductive dishes, Figure 1c).

However, in the case of the conductive dishes, the discharge current propagates to the ground directly through air (if there is an air gap between the HV electrode and the liquid surface) and the bulk of the liquid, Figure 1c. When the HV electrode was in contact with the surface of liquid samples in conductive dishes, the discharge was generated in the liquid itself, and the discharge current propagated through the bulk of the liquid sample only. In these tests $\pm 30 \mathrm{kV}$ voltage impulses were used to generate discharges in the liquid. This voltage level is close to the maximum energization voltage used in the tests with air gaps between the HV electrode and the surface of the liquid samples. It was found that, in the case when the electrode was in contact with the liquid sample, fluorescent light emission was very low, (no significant emission peak at $425 \mathrm{~nm}$ was resolved). Thus, direct discharges in liquid (no air gap between the HV electrode and the liquid surface) generated by the waveform used in the present study are not efficient for production of $\mathrm{OH}$ radicals in water based solutions. A potential reason for this is the relatively high conductivity of the tested solutions $(\sim 400$ $\mu \mathrm{S} / \mathrm{cm}$ ), which means that the process of formation of plasma streamers in the liquid samples stressed with the HV impulses used in the present tests (Section 2.1) is inefficient, and most of the discharge current dissipates through Joule conduction, without generation of $\mathrm{OH}$ radicals.

Thus, these results demonstrate that the transient plasma discharges which propagate through air and across the air/liquid interface are more efficient in production of $\mathrm{OH}$ radicals, as compared with the discharges which are generated directly in the liquid when the HV electrode is in contact with the liquid surface.

\subsection{CONCENTRATION OF OH RADICALS}

The intensities of fluorescent light emission obtained in Sections 3.2 and 3.3 have been used for evaluation of the concentration of $\mathrm{OH}$ radicals produced in water based solutions by the transient plasma discharges.

As discussed above, the fluorescent light peak at $425 \mathrm{~nm}$ indicates the presence and concentration of HTA acid, which can be related to the concentration of $\mathrm{OH}$ radicals. A calibration curve which links the fluorescence peak magnitude and HTA concentration has been obtained using solutions with known concentrations of HTA. It is known that the $\mathrm{OH}$ yield from oxidation of HTA by oxygen is 35\%, [18-20]. The concentration of $\mathrm{OH}$ radicals in the plasma treated samples was obtained using the fluorescent light intensity the calibration curve, and the yield factor.

The obtained concentrations of $\mathrm{OH}$ radicals for all tested voltages and topologies are shown in Figure 7. These $\mathrm{OH}$ concentrations are plotted as functions of the total delivered charge in each treatment case. The total charge was calculated by integration of the current waveforms for each individual case. It is shown that the concentration of $\mathrm{OH}$ radicals in the TA solutions increases linearly with the delivered charge and does not depend on voltage for the voltage levels tested in the present study. In the case of the direct contact of the high tension electrode with the liquid surface, the concentration of $\mathrm{OH}$ radicals is low: for example, based on the fluorescence light emission intensity produced by the TA solutions treated in plastic dishes, the concentration of $\mathrm{OH}$ radicals is less than 0.1 $\mu \mathrm{M}$, even after $7 \mathrm{~min}$ treatment time. The concentration of $\mathrm{OH}$ radicals observed in the samples treated in non-conductive 
dishes is slightly higher, $0.5-0.6 \mu \mathrm{M}$ after $7 \mathrm{~min}$ plasma treatment.
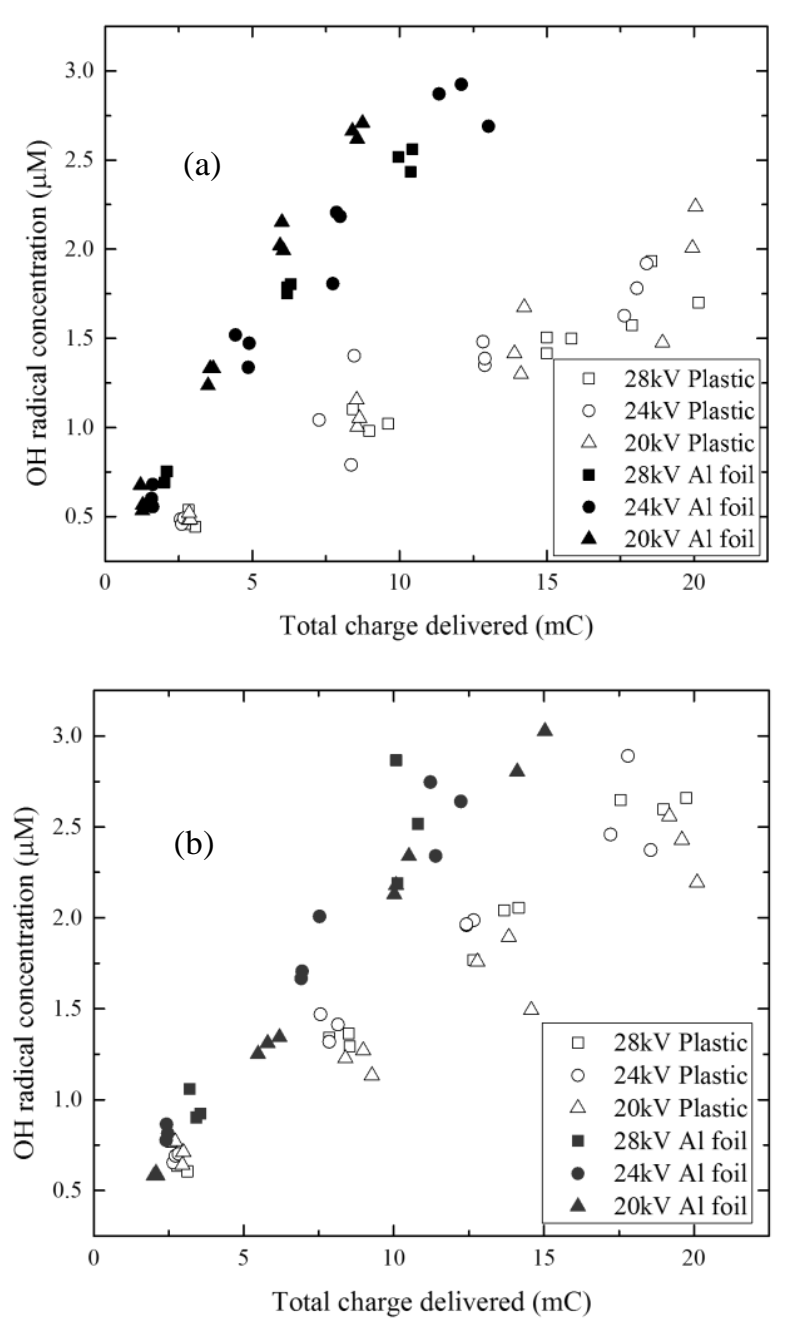

Figure 7. $\mathrm{OH}$ concentration as a function of total charge delivered by transient plasma discharges. (a), positive energization, non-conductive (plastic) and conductive ( $\mathrm{Al}$ foil lined) dishes; (b), negative energization, non-conductive and conductive dishes.

\section{CONCLUSIONS}

$\mathrm{OH}$ radicals have the highest oxidation capability amongst all oxygen-based reactive species with redox potential of $2.7 \mathrm{~V}$, [25]. Thus, these radicals can play an important role in chemical oxidation of organic molecules and in biological decontamination. Non-thermal plasmas are actively studied in order to establish their capability of generation of reactive oxygen and nitrogen species and their use in practical environmental and medical applications. Therefore, it is important to characterise production of the strongest oxidant (hydroxyl radicals) in water based solutions by non-thermal transient plasma discharges. Information on the concentration of $\mathrm{OH}$ radicals and their rate of production will help in optimization of practical cleaning and decontamination processes based on non-thermal transient plasma discharges. In the present work, production of hydroxyl radicals in TA water based solutions by the transient plasma discharges has been investigated. The concentration of plasma generated $\mathrm{OH}$ radicals was obtained by measuring the intensity of fluorescent light emitted by HTA acid, which is formed in water-based solution of terephthalic acid, as TA acid reacts specifically with $\mathrm{OH}$ radicals. The dependency of the concentration of the plasma generated $\mathrm{OH}$ radicals on discharge driving voltage, its polarity, and total delivered charge and treatment time was obtained.

Different discharge energization voltage levels were used in the present study to generate transient plasmas $( \pm 20, \pm 24$ and $\pm 28 \mathrm{kV}$ ) and two types of dishes (sample holders) were used to treat TA water based samples: non-conductive plastic dishes located on the grounded metallic holder, and conductive aluminum foil-covered dishes, also located on the grounded metallic support within the treatment test cell. In the first case the plasma discharges propagate vertically through air and then across air/liquid interface. In the second case, the discharges propagate only vertically and then the discharge current dissipates through the bulk of the liquid sample. A higher efficiency of $\mathrm{OH}$ radical production was observed in the latter case: for the conductive sample holders, the obtained specific production efficiency was $0.324 \mu \mathrm{M} / \mathrm{mC}$ for positive impulses, and $0.253 \mu \mathrm{M} / \mathrm{mC}$ for negative impulses. In the case of the nonconductivve dishes, the specific production efficiency was lower: $0.125 \mu \mathrm{M} / \mathrm{mC}$ for positive impulses and $0.171 \mu \mathrm{M} / \mathrm{mC}$ for negative impulses.

Indirect chemical processes with involvement of other reactive oxygen species such as ozone and hydrogen peroxide could also have an effect on $\mathrm{OH}$ radical production. For example, ozone molecules can be decomposed in water through a chain reaction catalyzed by hydroxyl radicals. Ozone reacts with $\mathrm{OH}$ radicals resulting in production of $\cdot \mathrm{O}_{2}^{-}$, then an electron will be transferred to ozone molecule to form $\cdot \mathrm{O}_{3}{ }^{-} \cdot \mathrm{O}_{3}{ }^{-}$ which in turn react with water molecules to form $\mathrm{OH}$ radicals $[26,27]$. However, in the current work, the ozone concentration generated in the test cell was minimal, less than $1 \mathrm{ppm}$, and it is believed that ozone based reactions did not make a significant contribution to the production of $\mathrm{OH}$ radicals in the present tests.

Another important finding of this paper includes the fact that the rate of $\mathrm{OH}$ production depends almost linearly on the total delivered charge. The concentration of the plasma produced $\mathrm{OH}$ radicals practically does not depend on the magnitude of $\mathrm{HV}$ impulses used to generate the transient discharges at the same delivered charge. Thus, it confirms that the total charge delivered by the plasma discharges defines the production rate of reactive species and plays an important role in the advanced oxygen processes.

A comparison of the concentrations of $\mathrm{OH}$ radicals generated by the transient plasma discharges in non-conductive and conductive dishes reveals that, in the case of the conductive dish, plasma discharges produce more $\mathrm{OH}$ radicals. Also, it has been shown that in the case when the high tension electrode is in touch with a surface of the treated liquid, the efficiency of $\mathrm{OH}$ production is low. In the present study, the maximum $\mathrm{OH}$ production efficiency of $1.39 \cdot 10^{-8} \mu \mathrm{M} / \mathrm{s}$ was achieved using negative energization of the $\mathrm{HV}$ electrode. This figure is higher than the production rate of $\mathrm{OH}$ reported in [19] for underwater discharges. In [28] and [29], steady-state plasma was used to generate $\mathrm{OH}$ radicals in water. The production rates 
reported in these papers are slightly higher than the rate of $\mathrm{OH}$ production achieved in the present paper, $(1-4.7) \cdot 10^{-8} \mathrm{M} / \mathrm{s}$ [28], and $1.67 \cdot 10^{-8} \mathrm{M} / \mathrm{s}$ [29]. However, these figures were obtained using continuous steady-state plasma treatment. In the current work, impulsive treatment was used (with a pulse repetition rate of 20 pulses per second), and it is therefore expected that with an increase in pulse repetition rate and/or treatment time, significantly higher $\mathrm{OH}$ production rates can be achieved. The results obtained in the present paper will help in optimization of $\mathrm{OH}$ production in liquids by transient plasma discharges.

\section{ACKNOWLEDGEMENTS}

The authors would like to thank the Department of Biomedical Engineering at the University of Strathclyde for access to their fluorescence spectrophotometer.

\section{REFERENCES}

[1] S. Li, I. Timoshkin, M. Maclean, M. Wilson, M. Given, S. MacGregor, T. Wang and J. Anderson, "Steady-State Corona Discharges in Atmospheric Air for Cleaning and Decontamination", IEEE Trans. Plasma Sci., Vol. 41, pp. 2871 - 2878, 2013.

[2] P. Lukes, E. Dolezalova, I. Sisrova and M. Clupek, "Aqueous-phase chemistry and bactericidal effects from an air discharge plasma in contact with water: evidence for the formation of peroxynitrite through a pseudosecond-order post-discharge reaction of $\mathrm{H}_{2} \mathrm{O}_{2}$ and $\mathrm{HNO}_{2}$ ", Plasma Sources Sci. Technol., Vol. 23, 015019, 15pp, 2014.

[3] D. Dobrynin, G. Fridman, G. Friedman and A. Fridman, "Physical and biological mechanisms of direct plasma interaction with living tissue", New J. Phys. Vol. 11, 11502, 2009.

[4] G. Fridman, A. D. Brooks, B. Manjula, A. Fridman, A. Gutsol, V. N. Vasilets, H. Ayan and G. Friedman, "Comparison of direct and indirect effects of non-thermal atmospheric pressure plasma on bacteria", Plasma Process. Polym., Vol. 4, pp. 370-375, 2007.

[5] S.Samukawa, M. Hori, S. Rauf, K. Tachibana, P. Bruggeman, G. Kroesen, J. Whitehead, A. Murphy, A. Gutsol, S. Starikovskaia, U. Kortshagen, J.P. Boeuf, T. Sommerer, M. Kushner, U. Czarnetzki and N. Mason, "The 2012 Plasma Roadmap", J. Phys. D: Appl. Phys., Vol. 45, 253001 (37pp), 2012.

[6] I. V. Timoshkin, M. Maclean, M. P. Wilson, M. J. Given, S. J. MacGregor, T. Wang and J. G. Anderson, "Bactericidal effect of corona discharges in atmospheric air". IEEE Trans. Plasma Science, Vol. 40, No. 10, pp. 2322-2333, 2012.

[7] H. Eto, Y. Ono, A. Ogino and M. Nagatsua, "Low-temperature sterilization of wrapped materials using flexible sheet-type dielectric barrier discharge", Appl. Phys. Letters, Vol. 93, 221502, 2008.

[8] S. Patil, T. Moiseev, N.N. Misra, P.J. Cullen, J.P. Mosnier, K.M. Keener and P. Bourke "Influence of high voltage atmospheric cold plasma process parameters and role of relative humidity on inactivation of Bacillus atrophaeus spores inside a sealed package", J. Hospital Infection, Vol. 88, pp.162-169, 2014.

[9] M. Sun and L. Cai, "Diagnosis of $\mathrm{OH}$ radicals in air negative pulsed discharges with nozzle-cylinder electrode by optical emission spectroscopy", IEEE Trans. Plasma Sci., Vol. 40, No. 5, pp.1395-1398, 2012.

[10] Z. Machala, I. Jedlovsky, L. Chladekova, B. Pongrac, D. Giertl, M. Janda, L. Sikurova, P. Polcic, "DC discharges in atmospheric air for biodecontamination - spectroscopic methods for mechanism identification", Eur. Phys. J. D, Vol. 54, pp. 195-204, 2009.

[11] E. Sysolyatina, A. Mukhachev, M. Yurova, M. Grushin, V. Karalnik, A. Petryakov, N. Trushkin, S. Ermolaeva and Y. Akishev, "Role of the Charged Particles in Bacteria Inactivation by Plasma of a Positive and Negative Corona in Ambient Air", Plasma Process. Polym., Vol. 11 No. 4, pp. 315-334, 2014

[12] J. Guo, K. Huang and J. Wang, "Bactericidal effect of various non-thermal plasma agents and the influence of experimental conditions in microbial inactivation: A review", Food Control, Vol. 50, pp. 482-490, 2014.

[13] P. Bruggeman, F. Iza, P. Guns, D. Lauwers, M. G. Kong, Y. A. Gonzalvo, C. Leys and D. C. Schram, "Electronic quenching of OH(A) by water in atmospheric pressure plasmas and its influence on the gas temperature determination by OH(A-X) emission" Plasma Sources Sci. Technol. Vol. 19, 015016, 7pp, 2010.

[14] H. Kim, K. Wright, I. Hwang, D. Lee, A. Rabinovich, A. Fridman, Y. Cho, "Effect of $\mathrm{H}_{2} \mathrm{O}_{2}$ and low $\mathrm{pH}$ produced by gliding arc discharge on the inactivation of Escherichia Coli in water", Plasma medicine, Vol. 1(34), pp. 295-307, 2011.

[15] A. Fridman, Plasma Chemistry, Cambridge University Press, 2008.

[16] S. Kanazawa, H. Kawano, S. Watanabe, T. Furuki, S. Akamine, R. Ichiki, T. Ohkubo, M. Kocik and J. Mizeraczyk, "Observation of $\mathrm{OH}$ radicals produced by pulsed discharges on the surface of a liquid", Plasma Sources Sci. Technology, Vol. 20, 034010(8pp), 2011.

[17] Y. Ikeda, A. Moon and M. Kaneko, "Development of microwaveenhanced spark-induced breakdown spectroscopy", Appl. optics, Vol. 49, n.13, pp. 95-100, 2010.

[18] S. Page, W. Arnold and K. Mcneill, "Terephthalate as a probe for photochemically generated hydroxyl radical", J. Environ. Monit., Vol. 12, pp. 1658-1665, 2010.

[19] S. Kanazawa, T. Furuki, T. Nakaji, S. Akamine and R. Ichiki, "Application of chemical dosimetry to hydroxyl radical measurement during underwater discharge", ICAES-2012, J. Phys.: Conf. Series 418(2013)012102 DOI:10.1088/1742-6596/418/1/012102.

[20] T. Mason, J. Lorimer, D. Bates and Y. Zhao, "Dosimetry in sonochemistry: the use of aqueous terephthalic ion as a fluorescence monitor", Ultrasonic Sonochemistry, Vol. 1, no.2, pp.s91 - s95, 1994.

[21] S. J. MacGregor, J. M. Koutsoubis and S. M. Turnbull, "The design and operation of a compact high-voltage, high pulse repetition frequency trigger generator", Meas. Sci. Technol., Vol. 9, pp. 1899-1905, 1998.

[22] B. Sun, M. Sato and J. S. Clements, "Optical study of active species produced by a pulsed streamer corona discharge in water" J. Electrostat., Vol. 39, pp. 189-202, 1997.

[23] P. Sunka, V. Babicky, M. Clupek, P. Lukes, M. Simek, J. Schmidt and M. Cernak, "Generation of chemically active species by electrical discharges in water" Plasma Sources Sci. Technol., Vol. 8, pp. 258-265, 1999.

[24] M. Sato, T. Ohgiyama and J. S. Clements, "Formation of chemical species and their effects on microorganisms using a pulsed high voltage discharge in water" IEEE Trans. Ind. Appl., Vol. 32, pp. 106-12, 1996.

[25] D. M. Stanbury, "Reduction potentials involving inorganic free radicals in aqueous solution", Adv. Inorg. Checm, Vol. 33, pp. 69-138, 1989.

[26] B. G. Ershov and P. A. Morozov, "The kinetics of ozone decomposition in water, the influence of $\mathrm{pH}$ and temperature", Russian J. Phys. Chem. A, Vol. 83, No. 8, pp. 1295-1299, 2009.

[27] J. Staehelin and J. Hoigne, "Decomposition of ozone in water in the presence of organic solutes acting as promoters and inhibitors of radical chain reactions", Environ. Sci. Technol., Vol. 19, n.12, pp. 1206-1213, 1985.

[28] S. Kanazawa, T. Furuki, T. Nakaji, S. Akamine and R. Ichiki, "Measurement of $\mathrm{OH}$ Radicals in Aqueous Solution Produced by Atmospheric-pressure LF Plasma Jet", Ecological Society of America Conf. 2012, http://www.electrostatics.org/images/ESA2012_N3.pdf

[29] M. Sahni and B. R. Locke, "Quantification of Hydroxyl Radicals Produced in Aqueous Phase Pulsed Electrical Discharge Reactors," Ind. Eng. Chem. Res., Vol. 45, pp.5819-5825, 2006.

[30] Y. Zhao, T. Wang, S. MacGregor, M. Wilson, M. Given and I. Timoshkin, "Investigation of plasma-induced methylene blue degradation using dielectric barrier discharge", Int'l. Conf. Gas Discharges and Their Applications, Orleans, France, pp. 566-569, 2014.

[31] Z. Machala, B. Tarabova, K. Hensel, E. Spetlikova, L. Sikurova and P. Lukes, "Formation of ROS and RNS in water Electro-sprayed through Transient Spark Discharge in Air and their Bactericidal effect", Plasma Process. Polym., Vol. 10, pp.649-659, 2013.

[32] H. Tresp, M.U. Hammer, J. Winter, K-D. Weltmann and S. Reuter, "Quantitative detection of plasma-generated radicals in liquids by electron paramagnetic resonance spectroscopy", J. Phys. D: Appl. Phys., Vol. 46, 8 pp. 435401-09, 2013 


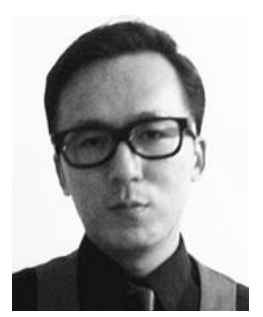

Sirui Li was born in Yunnan, China, in 1988. He received the B.Eng. (with honours) and M.Sc. degrees in electronic and electrical engineering from the University of Strathclyde, Glasgow, U.K., in 2010 and 2011. He is currently a Ph.D. student at the University of Strathclyde, majoring in non-thermal plasma discharge for air treatment and surface decontamination.

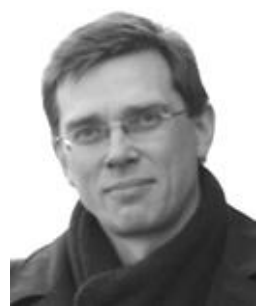

Igor V. Timoshkin (M'07-SM'14) received a degree in physics from the Moscow State University (Russia) in 1992, and the Diploma and the Ph.D. degree from the Imperial College of Science, Technology and Medicine, (London, UK) in 2001. After graduation from MSU he worked as a Researcher at Moscow State Agro-Engineering University, and then at the Institute for High Temperatures of Russian Academy of Sciences before moving to ICSTM in 1997. He joined the Department of Electronic and Electrical Engineering of the University of Strathclyde (Glasgow, UK) in 2001 as an Academic Visitor, where he became a Senior Lecturer in 2011. His research interests include properties of solid and liquid dielectric materials, electronics of plasma discharges in condensed media, practical applications of electrohydraulic and high-power ultrasound pulses, bio-dielectrics and effects of electromagnetic fields on biological objects.

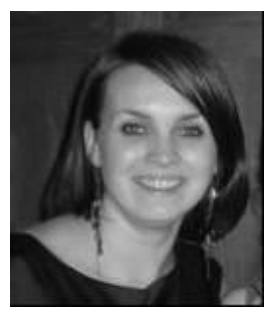

Michelle Maclean was born on the Isle of Lewis, Scotland, in 1980. She received the B.Sc. $\left(1^{\text {st }}\right.$ class honors) degree in microbiology and immunology in 2002, and the Ph.D. degree in electronic and electrical engineering in 2006, both from the University of Strathclyde, Glasgow, U.K. She is presently working as a Lecturer at the University of Strathclyde, and her interdisciplinary research work involves the development and application of novel electrotechnologies for biological decontamination and sterilization applications in clinical and public health environments. She is a member of The Society for General Microbiology and The American Society of Microbiology.

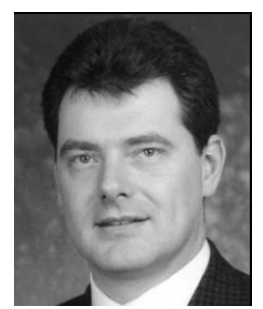

Scott J. MacGregor (M'95-SM14) received the B.Sc. and $\mathrm{Ph} . \mathrm{D}$. degrees from the University of Strathclyde, Glasgow, U.K., in 1982 and 1986, respectively. He is currently with the University of Strathclyde, where he became a Pulsed-Power Research Fellow in 1986, a Lecturer in pulsed-power technology in 1989, a Senior Lecturer in 1994, and a Reader and a Professor of highvoltage engineering in 1999 and 2001, respectively. He has been Dean of Engineering at the University of Strathclyde since January 2010. His research interests include high-voltage pulse generation, high-frequency diagnostics, high-power repetitive switching, high-speed switching, electronic methods for food pasteurization and sterilization, generation of high-power ultrasound (HPU), plasma channel drilling, pulsed-plasma cleaning of pipes, and stimulation of oil wells with HPU.

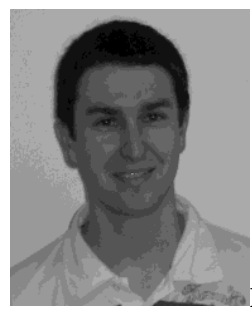

Mark P. Wilson (M'10) was born in Stranraer, Scotland, in 1982. He received the B.Eng. (with honours), M.Phil., and Ph.D. degrees in electronic and electrical engineering from the University of Strathclyde, Glasgow, U.K., in 2004, 2007, and 2011, respectively. He is presently working as a Teaching Associate at the University of Strathclyde, where he continues to investigate surface flashover of solids immersed in insulating oil. Mark is a member of the IEEE Nuclear and Plasma Sciences Society, from whom he received a Graduate Scholarship Award in 2011, the IEEE Dielectrics and Electrical Insulation Society, and the IET.

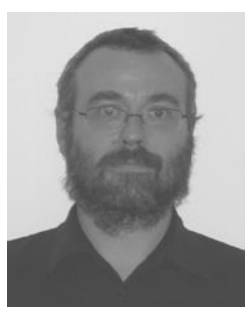

Martin J. Given (M'99-SM'11) is currently a Senior Lecturer in the Department of Electronic and Electrical Engineering at the University of Strathclyde. He received a degree in physics from the University of Sussex in 1981 and a Ph.D. in electronic and electrical engineering from the University of Strathclyde in 1996. His research interests include, ageing processes and condition monitoring in solid and liquid insulation systems, high speed switching and pulse power applications.

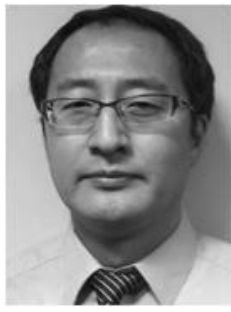

Tao Wang received the B.Eng. and M.Sc. degrees from Northeast China Dianli University (China) in 1993 and 1996, respectively, and the Ph.D. degree from the University of Strathclyde (Glasgow, UK) in 2005. He then joined the Newland Entech as a research fellow developing high efficiency industrial ozone generator. He joined the department of Electronic and Electrical Engineering of University of Strathclyde as a lecturer in 2010. His research interests include non-thermal gas discharges and their applications in gas synthesis, water disinfection and advanced oxidation process in water

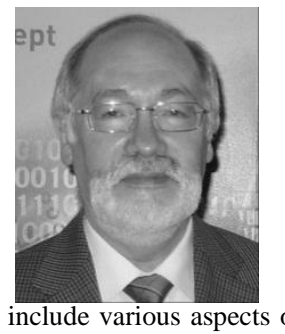

John Anderson was born in Glasgow, U.K., on 2 September 1942. He received the B.Sc. degree in applied microbiology in 1968, and the Ph.D. degree in fungal physiology in 1971, both from the University of Strathclyde, Glasgow. Since 1971, he has been with the Department of Bioscience and Biotechnology, University of Strathclyde, where he became a Professor of Microbiology and Head of the Department. He is currently an Emeritus Professor at the University of Strathclyde. His research interests include various aspects of food, biomedical and environmental microbiology with interdisciplinary collaboration on the application of electro-technologies for electronic pasteurization and sterilization. 